Psychother. Psychosom. 1981;35:77-79

\title{
Contents, Vol. 35, No. 2-3, 1981
}

\section{Contents}

Foreword and Introduction

Meyer, A.-E.; Bolz, W.

81

I. The General Setting

Bolz, W.; Meyer, A.-E

85

II. The Patient Sample: Overt and Covert Selection Factors andPrognostic PredictionsKimm,

H.J.; Bolz, W.; Meyer, A.-E 96

III. Our Focus Formulations: Practicability for Therapy; ContentAnalyses and Relation to Outcome and Other Variables

Gabel, H.; Deneke, F.; Meyer, A.-E.; Bolz, W.; Stuhr, U. 110

IV. Our Pluridimensional Evaluation System for Short Psychotherapy Outcome

Burzig, G.; Speidel, H.; Bolz, W.; Meyer, A.-E 134

V. Outcome Results in Psychological Tests

Stuhr, U.; Meyer, A.-E.; Bolz, W. 138

VI. Outcome Results by Clinical Evaluation Based on the Blind

Group Ratings

M. Meyer, A.-E.; Bolz, W.; Stuhr, U.; Burzig, G 